\title{
Argumentos de Humanização na Internação Compulsória em Dependência Química: a Favor e Contra
}

\author{
Almeida, Jéssica Pascoal Santos \\ Faculdade de Direito da Universidade de São Paulo. Grupo de Pesquisa em Bioética, Direito e Medicina \\ (Gbdm/USP), da Faculdade de Medicina da Universidade de São Paulo. — jessicapascoal@hotmail.com
}

Introdução a lei no. 10.216/01 - conhecida como Lei da Reforma Psiquiátrica e que instituiu um modelo de assistência baseado em práticas de humanização do atendimento em saúde mental prevê a possibilidade de internações psiquiátricas compulsórias (IPCs). Tais internações ocorrem quando não há nem o consentimento do indivíduo nem a autorização da família ou de outro responsável legal, mas uma determinação judicial. Não obstante, as IPCs são bastante debatidas, especialmente nos casos de dependência química. em qualquer nível encontram-se argumentos de humanização a favor ou contra a internação compulsória de dependentes de drogas. Objetivos Identificar e discutir os argumentos de humanização que justificam ou questionam a internação compulsória de dependentes químicos no Brasil. Métodos Revisão bibliográfica realizada com base em artigos disponíveis na biblioteca do Instituto Brasileiro de Ciências Criminais (IBCCRIM), maior acervo da América Latina neste seguimento, e na Biblioteca Virtual em Saúde (BVS), plataforma que conjuga as principais bases de dados da literatura sobre as Ciências da Saúde, tais como LILACS, IBECS, MEDLINE, SciELO, entre outras. Levantamento obtido utilizando-se os termos: internação e drogas. Artigos filtrados e analisados conforme abordagem sobre internação compulsória em dependência química. Resultados: a despeito da distinção técnica existente entre internação involuntária e internação compulsória, verifica-se na literatura o uso e a referência dos termos de forma indistinta e o emprego de tais expressões como se sinônimas fossem, o que dificulta, por consequência, a identificação exata da internação defendida ou questionada. Nota-se, também, que existem argumentos construídos com base em informações confusas e até mesmo inconsistentes ou incompletas. Encontrou-se nos textos jurídicos argumentos sem nenhuma evidência concreta indicada. em um dos textos houve o reconhecimento do antagonismo existente nas internações compulsórias, qual seja, de que, na prática a IPC é uma forma de punição dos dependentes químicos e, simultaneamente, um meio de acesso aos serviços de saúde. Conclusões As IPCs são utilizadas pelo Estado e estão amparadas pela lei, que determina que qualquer internação psiquiátrica somente será realizada mediante laudo médico circunstanciado e com indicação dos motivos da medida. no entanto, existem situações em que um suposto risco social parece extrapolar a esfera da saúde e da lei, e, por meio de uma ordem judicial, o sistema de saúde é intimado a controlar o risco via internação. a reflexão ética acerca dos casos de internação compulsória de dependentes químicos se apresenta como a forma mais adequada de se analisar os conflitos de valores existentes em tais circunstâncias, permitindo, ainda, a identificação dos argumentos de humanização mais seguros e eticamente defensáveis.

Almeida, Jéssica Pascoal Santos. Argumentos de Humanização na Internação Compulsória em Dependência Química: a Favor e Contra. In: Anais do Congresso Internacional de Humanidades \& Humanização em Saúde [= Blucher Medical Proceedings, num.2, vol.1]. São Paulo: Editora Blucher, 2014. ISSN 2357-7282

DOI 10.5151/medpro-cihhs-10825 